\title{
ANÁLISE DO PROGRAMA DE IMPLANTAÇÃO DE BIBLIOTECAS RURAIS “ARCA DAS LETRAS” NO MARANHÃO
}

\author{
Carlos Wellington Soares Martins* \\ Iris Maria Ribeiro Porto
}

RESUMO

Palavras-chave: Bibliotecas. Leitura. Política. Comunidades rurais.

\begin{abstract}
Este artigo apresenta o resultado de pesquisa no nível de Mestrado do Programa em Pós Graduação em Desenvolvimento Socioespacial e Regional da Universidade Estadual do Maranhão na linha de pesquisa Região, Movimentos Sociais e Territorialidades. A pesquisa tem como objetivo geral analisar o impacto nas formas de sociabilidade nas comunidades rurais de Codó - MA a partir da implantação do Programa de Bibliotecas Rurais "Arca das Letras" estabelecendo uma relação entre Estado e as políticas públicas de incentivo à leitura. A partir do delineamento dos objetivos e leitura extensiva de referencial teórico, montou-se um cenário permitindo comparações entre os relatórios divulgados e os contrastes com a realidade constatada, para tanto, considerou-se adequado o materialismo histórico-dialético como método a nortear a pesquisa. Como processo metodológico do ponto de vista da abordagem do problema, adotou-se a pesquisa qualitativa, quanto aos objetivos, caracteriza-se como pesquisa descritiva e quanto aos procedimentos técnicos, caracteriza-se como um levantamento. Como instrumento de coleta de dados, optou-se pela entrevista semiestruturada. As visitas foram realizadas durante o período de quatro meses. As comunidades visitadas totalizaram 489 famílias e I 82 entrevistas com os moradores das comunidades e oito agentes de leitura que atuam nessas comunidades. Evidencia-se, portanto, que as Políticas Públicas de incentivo à leitura são consideradas ineficientes, ainda são grandes os contrastes nas regiões evidenciadas que atestam sua ineficácia ao tentar diminuir o número de analfabetos e a democratizar os bens culturais. Conclui-se que o processo de democratização do acesso à informação torna-se, dessa forma, utópico se os atores envolvidos não se imbuírem desse significado. Estado e sociedade civil precisam medir esforços, em conjunto, para a solução desses problemas, apropriando-se do conceito de cidadania e pondo-o em prática no que tange à aplicação e continuidade do Programa.
\end{abstract}

\footnotetext{
* Mestre em Desenvolvimento Socio-espacial e Regional pela Universidade Estadual do Maranhão, Brasil. Doutorando no Programa de Pós-Graduação em Políticas Públicas da Universidade Federal do Maranhão, Brasil.

E-mail: cawell2000@uol.com.br.

** Doutora em Ciências Sociais pela Universidade Federal do Pará, Brasil. professora Adjunta da Universidade Estadual do Maranhão, Brasil.

E-mail: porto.iris@gmail.com.
}

\section{INTRODUÇÃO}

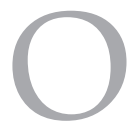

interesse pela análise e pesquisa sobre as políticas públicas de incentivo à leitura deu-se por vários motivos, entre eles, o mais importante foi o fato de creditar o papel transformador facultado pela leitura. Dessa forma, fez-se necessário um olhar crítico sobre as políticas públicas que são norteadas pelas práticas leitoras, ao mesmo tempo que houve a necessidade de elaborar um olhar investigativo para perceber se tais práticas não incorrem em assistencialismo, sem que alcancem realmente objetivos.

Nesse sentido, o Maranhão configurase como cenário de contrastes sociais, no qual a política partidária sobrepuja os anseios da população, a ponto de se tornar ambiente propício para análise de políticas públicas. Recorrentemente, programas e projetos são 
concebidos elencando enquanto discurso o desenvolvimento, contraditoriamente, vários são os indicadores que atestam a ineficácia dessas ações.

As comunidades rurais, distante dos grandes centros urbanos, acabam marginalizadas e excluídas desse processo, a maioria dos grandes projetos encontra-se em área urbana, e as políticas sociais não alcançam essa população. Quando se trata de leitura, a questão tornase mais desoladora em meio rural. Optouse, portanto, por se manter contato maior com essas comunidades e, especificamente, a questão das bibliotecas rurais e práticas de leitura evidenciadas nesses espaços, intentando realizar análise do discurso governamental de desenvolvimento e as realidades vivenciadas por esses sujeitos durante a implantação e execução de programa de incentivo à leitura, em meio rural.

Analisa-se como se efetivaram os processos de implementação e execução de políticas públicas, mais especificamente o Programa de Bibliotecas Rurais "Arca das Letras", elaborado pelo Ministério do Desenvolvimento Agrário (MDA). Esse programa data de 2003 e apresenta a finalidade de facilitar o acesso ao livro e incentivar a leitura em meio rural, através da instalação de bibliotecas e da formação de agentes de leitura. O MDA reforça a necessidade da participação das comunidades nas etapas de planejamento, desenvolvimento e gestão das arcas das letras. Contabilizam-se, nesse programa, mais de 8.743 arcas em todo o Brasil e a formação de 15 mil agentes de leitura, além da circulação de mais de 2 milhões de livros nas casas de 800 mil famílias de comunidades rurais (SOARES; CARNEIRO, 2010).

Grande parte dessas tipologias de comunidade encontra-se no município de Codó apresentando o quantitativo de 35 comunidades composta por mais de 1747 famílias atendidas. A análise do programa é relevante considerando a dimensão nacional e a grande quantidade de bibliotecas implantadas, bem como o número de famílias de comunidades rurais que são contempladas com o programa. Investiga-se, também, o retorno que tal ação ocasiona à região onde o programa foi implementado. Delinearamse, dessa forma, os seguintes objetivos para a pesquisa:

Objetivo geral:
- Analisar o impacto nas formas de sociabilidade nas comunidades rurais de Codó - MA a partir do Programa de Bibliotecas Rurais "Arca das Letras".

\section{Objetivos específicos:}

- $\quad$ Estabelecer a relação entre Estado, políticas públicas de incentivo à leitura e as práticas sociais decorrentes;

- Reconhecer as práticas sociais, políticas e culturais de leitura efetivadas no Maranhão e o panorama da realidade leitora no estado;

- Avaliar o espaço rural maranhense enquanto lócus de contrastes no universo da leitura e do acesso à informação.

A partir do delineamento dos objetivos e da leitura extensiva de referencial teórico, montou-se um cenário permitindo comparações entre os relatórios divulgados e os contrastes com a realidade examinada. Constata-se que a democratização do acesso à informação se configura como principal meio para que o indivíduo se sinta parte da construção de uma sociedade, através das relações sociais, propiciando o desenvolvimento local.

Diante dessas assertivas, algumas questões nortearam a pesquisa: a implantação do projeto acarreta, de alguma forma, benefícios para a região contemplada? Existem novas formas de sociabilidade decorrentes pela implantação do programa? Há um acompanhamento pelos órgãos mantenedores da ação em conjunto com a comunidade sobre a execução e avaliação da política?

Durante a pesquisa os seguintes pressupostos nortearam o trabalho:

a. As políticas públicas de incentivo à leitura, no país, são consideradas ineficientes, ainda são muito grandes os contrastes nas regiões evidenciadas, que atestam sua ineficácia ao tentar diminuir o número de analfabetos no país, e na democratização aos bens culturais;

b. A falta de articulação entre governo federal, Estados, Municípios e sociedade civil dificulta a elaboração e execução de políticas públicas de incentivo à leitura, por questões ideológicas, partidárias ou ineficiência no planejamento de ações; 
c. As comunidades rurais são excluídas da maioria das políticas públicas desenvolvidas, porque os sujeitos sociais não são percebidos. As ações não levam em consideração suas dinâmicas, estruturas produtivas e cultura, submetendo-as a uma política que não respeita as características de cada região, acabando por se tornarem políticas ineficazes em relação ao alcance de seus objetivos.

Esses pressupostos permitiram delimitar o caminho traçado para a pesquisa enquanto verificação entre teoria e empiria proposta nesse estudo.

\section{I Codó, referência do campo de pesquisa}

De acordo com Ferretti (2001), o município de Codó encontra-se na região do cerrado maranhense compreendendo a bacia do Rio Itapecuru, posição esta que facilitou o seu povoamento e o escoamento de sua produção agrícola. Encontra-se a uma distância de 305 quilômetros da capital do Maranhão, São Luís. O município foi criado através da Lei $n^{\circ} 13$ de 16 abril de 1896. Tem como limite os municípios de Aldeias Altas, Capinzal do Norte, Caxias, Coroatá, Gonçalves Dias, Governador Archer, Peritoró e Timbiras.

A origem do nome da cidade "Codó" é controversa. Várias histórias são contadas como a de que o nome do Município é decorrente da abundância de aves, como codorna ou codorniz, que havia em número grande na região. Outros afirmam, incluindo alguns pesquisadores, que a origem do nome remete ao Sudão Setentrional Africano, onde localiza-se a cidade de Kodok, de onde vieram alguns negros escravizados. E, por fim, a versão de que a palavra "Codó" significa "lugar de charco" ou "brejo" pelo fato de ocorrer algumas alagações decorrentes da cheia do Rio Itapecuru e seus afluentes (SOUSA, 2006).

Codó tem uma população de 118.072 habitantes, segundo dados aferidos no Censo 2010. A população masculina no total de 57.432, corresponde a $48,64 \%$ e a feminina $60.640 \mathrm{com}$ uma porcentagem de $51,35 \%$, como é comum no país a representação feminina ser maior do que a masculina.Sua zona urbana conta com 81.043 habitantes e 37.029 habitam na zona rural.
Apesar do número relevante de indústrias, questões como trabalho escravo e infantil ainda são presentes no cotidiano do Município, pois a grande parte dos filhos de trabalhadores rurais ajuda os pais na roça, contribuindo em casa, cuidando de irmãos mais novos, trabalhando em feiras e no comércio local (MOURA, 2009). Grande parte da população ainda sobrevive da agricultura de subsistência como indica Freitas (1990, p.46):

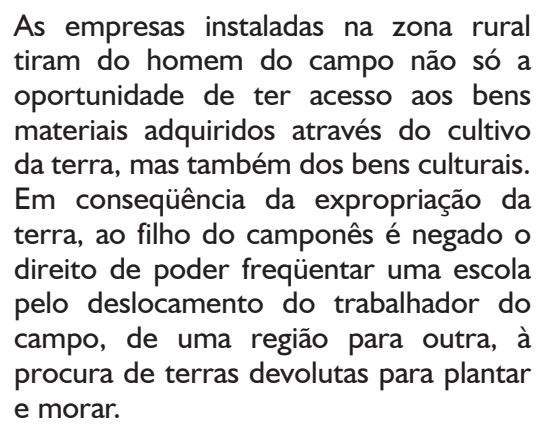

Os principais meios de subsistência, segundo Sousa (2006), são fruto de suas características rurais, agravado o problema de geração de renda com o crescimento da população urbana, principalmente para aquelas que residem nas áreas periféricas, pois não possuem qualificação profissional nem alternativas urbanas de geração de renda.

No que concerne ao programa analisado, evidencia-se um número expressivo de famílias atendidas, mas o que consta nos relatórios entra em contraste com a realidade delineando um longo caminho a percorrer e a necessidade de um olhar sociológico que analise essas práticas e suas reais intervenções em meio rural.

A partir da delimitação da área de estudo, de variáveis e caracterização do Município, identifica-se aportes importantes quanto ao direcionamento e caminho a ser percorrido durante a investigação especificada na metodologia e análise do objeto em estudo.

\section{I.2 Dos procedimentos metodológicos}

Com a delimitação da historicidade, objetivos, recortes epistemológicos e pressupostos se torna necessário a utilização de um método que permite o alcance dos objetivos 
da pesquisa. Foram realizadas leituras acerca das categorias de análise definidas: Estado e políticas públicas, leitura, direitos sociais e acesso à informação. A partir dessa postura, considerouse adequado o materialismo histórico-dialético como método a nortear a pesquisa.

O método não pode ser considerado um conjunto de regras formais aplicadas a determinado objeto em recorte, tampouco um conjunto de regras que o sujeito que pesquisa escolhe segundo sua vontade. Marx (1968) coloca o sujeito no papel de protagonista da pesquisa, com a tarefa de não apreender a aparência, mas a essência, sua estrutura e dinâmica, o sujeito tem que se apoderar da matéria em todos os pormenores, possibilitando a análise das mais diversas formas de desenvolvimento, percebendo, inclusive, as conexões existentes entre elas.

Para Marx (1968), por exemplo, implica, a verdade, em uma determinada posição ou perspectiva do sujeito que pesquisa, situação que favorecerá ao pesquisador extrair, em sua relação com o objeto, suas múltiplas determinações (NETTO, 2011).

Como processo metodológico do ponto de vista da abordagem do problema, adotouse a pesquisa qualitativa pelo fato de se acreditar que responde à questões particulares, apontando níveis de realidade que não podem ser quantificados. A pesquisa qualitativa é a mais indicada por trabalhar com o universo dos significados, valores, crenças e por compor a realidade social, propiciando a compreensão sobre a ação do homem enquanto ser reflexivo e com capacidade de interferir em sua realidade (MINAYO; DESLANDES; GOMES, 2010).

Quanto aos objetivos, caracteriza-se como pesquisa descritiva que é compreendida por Gil (1991) como a descrição das características de determinada população ou fenômeno e também as relações entre variáveis, pretendendo em alguns casos determinar a natureza entre essa relação.

Quanto aos procedimentos técnicos, caracteriza-se como um levantamento, que segundo o mesmo Gil (2004) constitui-se enquanto interrogação direta dos sujeitos da pesquisa. Essa forma de procedimento não demanda que sejam pesquisados todos os integrantes da população estudada, através da análise de um grupo significativo de pessoas ligadas ao objeto de estudo, as respostas obtidas permitem mensuração, delineando-se conclusões correspondentes aos dados coletados.

Como processo operativo optou-se em iniciar a pesquisa documental, consultas ao site do MDA, da Secretaria de Reordenamento Agrário (SRA) e do Portal Arca das Letras, onde, a partir da análise de documentos como relatórios, indicadores, manuais, guias, podese realizar comparações entre o que consta nos documentos e a realidade apresentada, seguido por pesquisa bibliográfica, através de consultas e análises críticas da literatura referente ao objeto pesquisado.

Após a consulta e estudo do arcabouço teórico, partiu-se a campo para realizar a coleta de dados nas comunidades que tiveram o programa implantado. Desde o início da pesquisa, foi mantido contato informal com as comunidades, o que contribuiu para a elaboração dos instrumentos de coleta de dados. Em relação ao acesso às comunidades e líderes comunitários, contou-se com o apoio da Organização NãoGovernamental (ONG) Plan que tem como foco de sua atuação a defesa dos direitos da infância e possui unidade em Codó.

As visitas foram realizadas durante o período de quatro meses. As comunidades visitadas foram Boqueirão (Projeto de Assentamento INCRA); Buriti Corrente (Agricultura familiar); Canto do Cocho (Agricultura familiar); EFA Codó (Escola Família Agrícola); Eira II (Agricultura familiar); Irmã Rita Loren (Projeto de Assentamento INCRA); Montevideo I (Agricultura familiar) e Rumo (Agricultura familiar), totalizando 489 famílias e 182 entrevistas com os moradores das comunidades e oito agentes de leitura que atuam nessas comunidades.

Como o objetivo do programa "Arca das Letras" é o acesso à leitura pelas comunidades distantes de grandes centros urbanos, considerou-se importante que não fossem delimitadas faixa etária e gênero, uma vez que essa ação é direcionada a todos os moradores de comunidades rurais não justificaria delimitar categorias.

Como instrumento de coleta de dados, optou-se por entrevista semiestruturada que, segundo Triviños (2010), é importante meio de coleta de dados. Os sujeitos foram submetidos a várias entrevistas, com a intenção, não só de 
obter o máximo de informações, mas de lograr variações nas respostas. Utilizou-se, para registro das entrevistas, gravador, câmera digital e caderno de notas.

As entrevistas abarcaram os Secretários de Cultura e Educação do Município de CodóMA, com o intuito de frisar a articulação entre os gestores e o programa e seu retorno social para o Município. A Coordenadora de Ação Cultural do MDA, a gestora do programa e a representante estadual do MDA participaram da pesquisa através de questionários enviados por e-mail, visto a distância e a agenda das mesmas não oportunizarem o encontro para a entrevista.

A relevância do estudo apresenta-se nos mais diferentes âmbitos, o programa irá completar dez anos de atuação e encontra-se, praticamente, em todos os Estados da Federação, o que reforça o caráter da necessidade de uma análise. Importante salientar que a temática de incentivo à leitura e bibliotecas assumiu papel de destaque nos discursos governamentais, reforçando uma questão ideológica passível de investigação.

Como contribuição para o debate acadêmico, as categorias de análise, presentes nesse estudo, representam a preocupação científica em investigar processos sociais que influenciam diretamente as dinâmicas e formas de sociabilidade, a relação entre Estado e políticas públicas de leitura e acesso à informação e a relação entre direitos sociais e comunidades rurais. Na seção posterior apresentar-se-ão os resultados oriundos da pesquisa documental (relatórios, cartilhas, planos, materiais de divulgação do programa e site oficial do Arca das Letras) e de campo (fala da coordenadora, da gestora do programa, responsável pela delegacia federal no Maranhão, agentes de leitura e moradores das comunidades pesquisadas).

\section{PROGRAMA DE IMPLANTAÇÃO DE BIBLIOTECAS RURAIS "ARCA DAS LETRAS"}

Durante o Governo Lula, em seu segundo mandato, os Ministérios da Cultura (MinC) e da Educação (MEC) elaboraram o Plano Nacional do Livro e Leitura (PNLL), como política de incentivo à leitura apresentando, como principal objetivo, zerar o número de Municípios sem bibliotecas e otimizar as que funcionavam de forma precária.

Dentre os objetivos do PNLL, destacamse: permitir o acesso e democratização da informação para os não-leitores e para aqueles que estão excluídos da possibilidade do acesso ao livro, independente de barreiras geográficas (BRASIL, 2007). Partindo desse pressuposto, o Ministério do Desenvolvimento Agrário (MDA) elaborou um Programa de Criação de Bibliotecas Rurais conhecido como "Arca das Letras" que visa à democratização e facilitação ao acesso à leitura por parte das comunidades rurais, com a entrega de arcas com acervo variado e escolha de agentes de leitura para atuarem enquanto mediadores na socialização desse acervo.

As primeiras bibliotecas "Arca das Letras" foram implantadas como projetos pilotos em cinco comunidades rurais do semiárido de Pernambuco e da Paraíba e no estado do Rio Grande do Sul, entre maio e julho de 2003. Naquelas localidades, foi desenvolvida, avaliada e aprimorada a metodologia de implantação de bibliotecas do MDA para o meio rural brasileiro (DANTAS, 2011).

O Programa "Arca das Letras" foi premiado, com menção honrosa, pelo Prêmio Vivaleitura no ano 2009, pela Organização dos Estados Ibero-Americanos para a Educação, a Ciência e a Cultura, como experiência abrangente e relevante para o país, e já cruzou as fronteiras. Algumas experiências internacionais de cooperação técnica solidária de doação de bibliotecas e de compartilhamento de metodologia foram desenvolvidas em TimorLeste, Cuba, Moçambique e na Colômbia (SOARES; CARNEIRO, 2010).

A implantação de programa como o "Arca das Letras", que caracteriza-se como facilitador de acesso ao livro e incentiva a leitura no meio rural brasileiro, através da instalação de bibliotecas e da formação de agentes de leitura, carece de um olhar que perscrute, melhor, a intervenção efetiva nas comunidades rurais atendidas.

Em 2017, totaliza o número de 36.144 famílias atendidas e uma distribuição de 37.400 livros. O Programa já distribuiu aproximadamente um total de 1.759.601 livros em todo o território nacional e, possui aproximadamente onze mil bibliotecas implantadas. (MINISTÉRIO DO DESENVOLVIMENTO AGRÁRIO, 2018). 
O Programa de Bibliotecas Rurais "Arca das Letras" já se estabeleceu no estado do Maranhão em aproximadamente 447 comunidades nos territórios da Baixada Ocidental, Cocais, Vale do Itapecuru, Baixo Parnaíba, Campos e Lagos, Lençóis Maranhenses, Médio Mearim, Alto Turu e Gurupi. As arcas atendem 38.713 famílias com características diversas compreendidas em Agricultura familiar, Projeto de Assentamento (INCRA), remanescente de quilombos, indígenas, Escola Família Agrícola (EFA), assentamento estadual, colônia de pescadores, Projeto de Crédito Fundiário e Casa Família Rural.

O cuidado a ser tomado é em relação à estrutura de ações, para que elas não se restrinjam apenas a distribuição de livros, mas também a oportunizar uma ação cultural eficaz. Pode-se pensar em uma ação cultural dialógica e libertadora em que o usuário possa interagir com a atividade, refletindo sobre o tema apresentado. A partir da discussão é que o indivíduo toma conhecimento da realidade e faz a análise crítica do letramento, da alfabetização que envolve a compreensão também crítica da leitura e, por conseguinte, da biblioteca (FREIRE, 1989). Essa ação dialógica encontra, na proposta de Freire (1982), ressonância com o intuito de fazer dos indivíduos, membros partícipes de sua realidade.

Nas subseções posteriores, apresentarse-á informações sobre o programa: composição, acervo, infraestrutura, ações e agentes de leitura, tendo por base o documento "Implantação de Bibliotecas Rurais: manual para agentes de leitura e multiplicadores do programa Arca das Letras", relacionando as diretrizes do documento com as falas da gestora, coordenadora, da responsável pela delegacia federal no Maranhão e, principalmente, as falas e vivências dos moradores das comunidades rurais pesquisadas.

\section{I A composição da "arca das letras"}

O Programa em referência deve ser desenvolvido, segundo orientações básicas, com a participação dos moradores das comunidades em todas as suas fases. Para receber a biblioteca, a comunidade rural deve organizar uma reunião para discutir como quer sua biblioteca; função social, educacional e cultural; a responsabilidade dos moradores de cuidar, administrar e ampliar os acervos; e o compromisso dos Agentes de
Leitura em controlar os empréstimos dos livros e organizar atividades de valorização da biblioteca e de incentivo à leitura (RODRIGUES, 2010).

Conforme relatado pela coordenadora à metodologia de ação segue a seguinte ordem:

a. Consulta comunitária. Os moradores devem realizar reunião para preencher coletivamente formulário que contém informações sobre níveis de escolaridade presentes na comunidade; tipos de produção agrícola e produção cultural, preferências e necessidades de informação;

b. Moradores devem indicar as pessoas que serão formadas como Agentes de Leitura. Devem ser indicados de 2 a 3 pessoas para atuarem em revezamento e em parceria na comunidade;

c. Acervo deve ser formado conforme indicações da comunidade;

d. Biblioteca deve ser instalada em espaço comunitário (exceto em escola) ou na casa de algum morador que disponha de algum tempo livre para atender a comunidade;

e. Gestão coletiva e autônoma das bibliotecas: as comunidades devem manter as reuniões para discutir o acervo e o funcionamento da biblioteca, buscando no MDA/Coordenação Arca das Letras as orientações e apoio necessários para resolver os problemas que surgirem.

Durante a reunião de consulta, um dos moradores deve ser escolhido para ser o responsável pelo preenchimento do Formulário de Consulta Comunitária onde descreve as características da comunidade e os aspectos definidos para o planejamento da biblioteca, tais como: o local onde a biblioteca será instalada na comunidade; as áreas temáticas de interesse para formação do acervo; os dados dos voluntários que serão capacitados como Agentes de Leitura; se alguém pode fabricar o móvel arca no município, agilizando a chegada da biblioteca (SOARES, 2011).

Para implantação da biblioteca, as lideranças locais devem organizar um pequeno mutirão para apresentá-la à comunidade. É neste momento que os moradores conhecerão o acervo e as regras de funcionamento. $\mathrm{O}$ intuito da ação é fazer com que a biblioteca torne-se patrimônio da comunidade, que deve se esforçar para que a leitura se torne hábito cotidiano e prazeroso. 
Em Codó, as comunidades rurais possuem as mais diferentes tipologias como: Projeto de Crédito Fundiário, Quilombolas, Agricultura Familiar, Projeto de Assentamento INCRA, Escola Família Agrícola e Assentamento Estadual, dessas algumas se encontram em situação de conflito na questão de posse de terras. A maioria dessas comunidades encontram-se distante da área urbana da cidade de Codó, algumas localizando-se em regiões fronteiriças de outros municípios como Caxias, Peritoró e Timbiras. Em relação ao programa no município, toda a ação teve como colaborador importante a Pastoral da Criança que foi a responsável pela comunicação com as comunidades, explicação sobre o programa, articulação para a construção dos móveis arcas e a distribuição dos mesmos para representantes das comunidades.

A maioria dos entrevistados, que residem nas comunidades rurais escolhidas, afirmam que não participaram da consulta para a implantação do programa, e, também não foram consultados sobre a escolha do agente de leitura. Todos os entrevistados foram unânimes em relatar que a escolha do agente de leitura aconteceu por indicação da representante da Pastoral da Criança, cabendo ao próprio agente a responsabilidade da divulgação da ação e de sua efetivação.

Originalmente, no projeto piloto, os móveis eram construídos por apenados numa ação em parceria com o Ministério da Defesa e o Departamento Penitenciário Nacional, onde os trabalhadores responsáveis pela fabricação das arcas recebiam uma bolsa e concessão de redução da pena pelo trabalho. As arcas são móveis produzidos especificamente para as comunidades rurais, com desenho e tamanho padrão para facilitar a sua reprodução. Os municípios podem fabricar suas arcas em marcenarias da região para estimular o trabalho local.

A escolha do formato e o nome "arca", segundo a gestora do programa, foi uma forma de aproximação do vocabulário regional, onde todos os moradores de áreas rurais sabem o que é uma arca, além do formato possibilitar a remoção do material para qualquer lugar por possuir rodas e não ser um móvel muito grande, assim não ocupando muito espaço no local onde estiver instalada.

Em Codó, foi montada uma parceria com marcenaria local para a construção dos móveis arca, pois a montagem é considerada fácil e mais econômica do que fosse necessário o transporte dos móveis de Brasília para os demais estados da federação. Em algumas comunidades não se pode localizar o móvel arca pelo fato da pessoa responsável não residir mais na comunidade e também por ser desconhecido o paradeiro do móvel.

Em uma das falas, importante frisar, tanto pelo contexto de forma quanto pelo simbólico, um dos moradores referiu-se ao móvel como "o caixãozinho". Em grande parte das casas onde estava alojado o móvel arca, a sua utilidade não era o de repositório de livros, mas já servindo para abrigar outras coisas como: roupas, brinquedos e até mesmo televisão.

\section{I.I Acervo, infraestrutura e ações}

A biblioteca "Arca das Letras" começa com um acervo contendo cerca de 200 livros e coleções de histórias em quadrinhos, os gibis. Os títulos estão distribuídos em literatura brasileira e estrangeira para crianças, jovens e adultos, livros didáticos para pesquisa escolar e livros técnicos e especializados nas áreas de interesse da comunidade para desenvolver seus projetos produtivos, educacionais, culturais e de apoio ao exercício da cidadania.

Segundo a responsável pela Delegacia Federal do MDA no Estado do Maranhão o acompanhamento é realizado por um servidor onde, no acompanhamento de outras ações do ministério para qualquer cidade, tentamos observar se naquela cidade o programa foi implantado e como está seu andamento e se procede o desenvolvimento dos empréstimos dos livros. A entrevistada também comenta sobre alguns entraves para a execução do programa, um deles a falta de recurso para a construção da biblioteca, o Ministério entra com a doação dos Acervos e tentamos obter parceria com algumas prefeituras para a doação da construção do móvel.

Em relação à avaliação da repercussão do programa no estado, a responsável pela delegacia estadual do MDA considera satisfatória, pois no nosso Estado já foram implantadas, mas de 400 Bibliotecas Rurais e para esse ano (refere-se a 2012) já está previsto entrega de mais de 400. Segundo a entrevistada, a ação tem uma importância para o Estado quando propicia a leitura nas áreas rurais 
que são esquecidas por alguns órgãos públicos, através da introdução de bibliotecas.

Sobre a divulgação do Programa, a Coordenadora de Ação Cultural do MDA reforça que a mais importante é a que é feita junto às comunidades, utilizando programas de rádio, eventos ligados à agricultura familiar e à reforma agrária. A operacionalização é realizada de forma simples: basta que a comunidade indique as pessoas para que tenham a formação como agentes de leitura para que sejam adquiridos os móveis (através da doação da arca), organiza-se o acervo e então é marcado a formação e entrega do kit da biblioteca.

Ainda segundo a entrevistada, a execução é um processo que acontece de forma diferente em cada lugar; muda muito de comunidade para comunidade, de Município para Município, de Estado para Estado. Em alguns lugares a biblioteca funciona em consonância com os objetivos, e em outros não funciona a contento.

$O$ acompanhamento é constante, mesmo à distância, reforça a idealizadora, de vez em quando entramos em contato com os agentes de leitura, fazemos encontros territoriais, estaduais e nacionais para trocarmos impressões sobre o que está acontecendo em cada localidade. Ao identificarmos os problemas, marcamos as visitas locais para discutir a forma de se resolver problemas (geralmente, quando a biblioteca não funciona, basta uma reunião para resolver isso e realizar a troca de lugar de instalação). O acompanhamento também é feito por telefone, por visitas comunitárias, por sorteio ou por aproveitamento de agendas do programa em locais próximos, nos encontros territoriais, em alguns locais (como Bacabal, onde são feitos encontros municipais mais frequentes), encontros estaduais e nacionais.

Em cada nível de abrangência de encontro se reduz a participação local por causa dos custos, mas sempre deve haver representantes de comunidades (nível municipal), de Municípios (territorial e estadual) e de Estado (encontro nacional). As visitas de avaliação têm um formulário que é discutido com os agentes de leitura. Esse formulário dá informações para que se promova melhoria nas bibliotecas.

As estratégias, para melhorar as ações, costumam ser: troca da biblioteca de lugar dentro da comunidade; envio de novos livros para atualização do acervo; realização de nova capacitação de agentes de leitura. No Município, contraditoriamente, esse retorno dado pelo MDA não ocorre há muito tempo, o que, segundo os entrevistados, fragiliza muito a ação, pois os livros não são renovados e não ocorre capacitações para possíveis novos agentes de leitura.

\subsection{0 agente de leitura}

Os agentes de leitura, do programa "Arca das Letras" são membros da comunidade, voluntários que, por meio de consulta comunitária, são selecionados para atuarem como mediadores no processo de instalação e execução do programa. Todos os agentes de leitura entrevistados para a pesquisa afirmaram serem lavradores e grande parte não concluiu o ensino fundamental.

Basicamente, ele é responsável por dinamizar as ações e fazer com que a biblioteca seja utilizada pela comunidade, na maioria das vezes, a arca, contendo o acervo, fica na própria casa do agente de leitura, conforme já referenciado. A coordenação do programa considera que, se a mesma estivesse em uma escola, ou associação, ficaria restrita a um público específico, o que não condiz com o objetivo do programa, que visa alcançar o maior número de moradores da comunidade, oportunizando ao acesso ao livro, leitura e geração de um novo espaço de sociabilidade da comunidade. Os Agentes de Leitura podem criar práticas de incentivo à leitura e, ainda, organizar eventos.

Para atuarem como agentes de leitura, os membros escolhidos pela comunidade recebem uma capacitação técnica do Programa, certificada pelo Ministério do Desenvolvimento Agrário (MDA), onde aprendem a rotina básica de empréstimo de uma biblioteca e noções para realização de campanhas para ampliação do acervo, na organização de eventos culturais e no estímulo da leitura como prática social e cultural. O MDA reforça que o pedido da instalação da biblioteca seja decorrente de reivindicação da comunidade, sendo intermediada pelo poder público local ou não. Grande parte das comunidades rurais do Município de Codó apresentou intervenção do poder público local.

A maioria dos agentes de leitura entrevistados afirma que a divulgação dos serviços oferecidos pela biblioteca, na 
comunidade, foi verbal, melhor forma de divulgação pelos agentes, visto as comunidades serem pequenas. Os agentes de leitura também são enfáticos na importância da instalação da biblioteca rural "Arca das Letras" nas comunidades.

Dentre os serviços oferecidos estão: empréstimo domiciliar, o empréstimo local, auxílio às pesquisas escolares e algumas atividades de incentivo à leitura. Os agentes de leitura têm o mesmo entendimento em relação à facilidade de acesso aos usuários. Verificou-se que a maioria das comunidades não seguiu os critérios do princípio de gestão, proposto pelo MDA, não realizando, por exemplo, campanhas de doação de livros e não proporcionando práticas de estímulo à leitura e letramento, o que acaba por contribuir para que a arca fique esquecida.

O governo municipal local desconhece totalmente a ação, tanto a Secretaria de Cultura quanto a de Educação, no momento em que os representantes de cada pasta foram entrevistados, alegaram que a ação foi efetivada durante a gestão anterior e que ambos desconheciam o programa, não havendo interesse na utilização da ação em seus planos de governo.

É importante frisar que algumas iniciativas pontuais são positivas: uma agente multiplicou a quantidade de livros, sendo necessária até a aquisição de uma estante ao lado do móvel "arca" para receber as novas aquisições, outra agente, juntamente com o marido, se responsabilizou por momentos de contação de histórias que se tornaram constantes na comunidade, bem como o empréstimo de livros que ocorre numa frequência considerada razoável pela agente. Grande parte dos agentes de leitura aponta a dificuldade de conciliar seus afazeres com a função, e atribui a falta de capacitação constante como outro entrave para a execução do Programa. Além de não contarem com o apoio do Governo Municipal.

\section{CONCLUSÃO}

Ficou evidente, com a execução da pesquisa, que o processo de descentralização (quando a gestão é compartilhada entre poder local e sociedade civil) ainda é presente e que existe a indecisão acerca dos papéis a serem executados por cada sujeito social envolvido no processo. Em relação a Codó, o desconhecimento do programa "Arca das Letras" chamou a atenção, pois é grande entre moradores do centro e até mesmo dos moradores da zona rural, que foram público-alvo da investigação. Essa questão agrava-se mais ainda pela constatação de que o poder público local também desconhece o programa e não tem uma noção explicita de como integrar a iniciativa ao Plano Municipal, mesmo com as inúmeras possibilidades apresentadas.

Foi visível também que, devido ao não acompanhamento do programa, algumas arcas e livros se perderam, outras ganharam outra serventia, totalmente diversa da proposta pela ação. Vale ressaltar que foram encontradas algumas ações que definiram significados em suas comunidades como a ampliação de acervo mediante doação, contação de histórias e a utilização dos materiais como suporte às aulas. Da mesma forma, adultos e idosos fazem uso de alguns títulos, mas esses resultados são mais pela disponibilidade e boa vontade de determinados agentes de leitura do que precisamente por alguma orientação oriunda por parte do Ministério que idealizou o Programa.

Mesmo com a quantidade de "arcas" entregues e a variedade de famílias atendidas pelo programa, a ação encontra-se ainda de forma incipiente, não encontrando ressonância na comunidade quanto ao letramento e alfabetização, questão reforçada pelas falas dos entrevistados.

Ressalta-se que, muitos Municípios, por meio de suas Secretarias de Educação e Cultura, desconhecem totalmente a existência da ação, dificultando a construção de novas parcerias que fomentem o programa.

Os pressupostos, portanto, foram confirmados na investigação e as questões norteadoras respondidas da seguinte forma:

a. O programa, enquanto realidade aplicada, não oportuniza, de forma representativa, benefícios para as comunidades que foram atendidas, haja vista o grande desconhecimento, por parte dos moradores, da existência do programa, bem como o fato de não estar incluído em uma política cultural e educacional do Município, o que contribui ainda mais para que a ação não atinja os objetivos propostos; 
b. Um dos objetivos do programa é oportunizar a criação de um novo espaço de sociabilidade para as comunidades atendidas pela ação, no entanto, passado a euforia inicial do ato do recebimento das "arcas", gerando a princípio acesso e uso, o que foi constatado é que muitas se perderam ou tiveram um outro uso que não corresponde ao proposto pelo programa;

c. O não acompanhamento da ação, nas três esferas de poder (Federal, Municipal e Estadual) foram identificados como fatores que contribuíram para o enfraquecimento do Programa, revelando que esse tipo de política não pode ficar desarticulada de um plano de governo e de constantes análises que redirecionem as estratégias de ação.

Evidencia-se, portanto, que as Políticas Públicas de incentivo à leitura são consideradas ineficientes, ainda são grandes os contrastes nas regiões evidenciadas que atestam sua ineficácia ao tentar diminuir o número de analfabetos e a democratizar os bens culturais. Conclui-se que o processo de democratização do acesso à informação torna-se, dessa forma, utópico se os atores envolvidos não se imbuírem desse significado. Estado e sociedade civil precisam medir esforços, em conjunto, para a solução desses problemas, apropriando-se do conceito de cidadania e pondo-o em prática no que tange à aplicação e continuidade do Programa.

Artigo recebido em 15/0I/20I8 e aceito para publicação em 07/06/2018

\section{ANALYSIS OF PROGRAM OF RURAL LIBRARIES “ARCA DAS LETRAS" IN THE MARANHÃO}

ABSTRACT This article presents the results of research at the Masters level of the Programa de Pós-Graduação em Desenvolvimento Socioespacial e Regional of the Universidade Estadual do Maranhão in the research line Region, Social Movements and Territorialities. The research has the general objective of analyzing the impact on the forms of sociability in the rural communities of Codó - MA since the implementation of the Programa de Implantação de Bibliotecas Rurais "Arca das Letras", establishing a relationship between the State and public policies to encourage reading. Based on the delineation of the objectives and extensive reading of the theoretical reference, a scenario was set up allowing comparisons between the published reports and the contrasts with the verified reality. Therefore, historical-dialectical materialism was considered as a method to guide research . As a methodological process from the point of view of the problem approach, the qualitative research was adopted, regarding the objectives, characterized as a descriptive research and as for the technical procedures, it is characterized as a survey. As an instrument of data collection, the semi-structured interview was chosen. The visits were carried out during the four-month period. The communities visited totaled 489 families and 182 interviews with community dwellers and eight reading agents who work in these communities. Thus, it is evident that the Public Policies to encourage reading are considered inefficient, the contrasts in the regions evidenced that prove their inefficacy in trying to reduce the number of illiterates and to democratize the cultural assets are still great. It is concluded that the process of democratization of access to information becomes, therefore, utopian if the actors involved do not imbue themselves with this meaning. The State and civil society must jointly strive to solve these problems by taking ownership of the concept of citizenship and putting it into practice with regard to the implementation and continuity of the Program.

Keywords: $\quad$ Libraries. Reading. Policy. Rural communities. 


\section{REFERÊNCIAS}

BRASIL. Ministério da Cultura. Plano Nacional do Livro e Leitura. Brasília, DF: MINC, 2006.

BRASIL. Ministério do Desenvolvimento Agrário. Relatório estadual de bibliotecas Arca das Letras entregues no Maranhão. 2010. Disponível em: <http://comunidades.mda.gov. $\mathrm{br} /$ dotlrn/clubs/arcadasletras/maranhoma/ one-community? page $=5 \&$ data_id $=2154224>$. Acesso em: 12 maio 2011.

BEHRING, Elaine Rossetti; BOSCHETTI, Ivanete. Política social: fundamentos e história. 5 ed. São Paulo: Cortez, 2008.

DANTAS, Jadiana de Paiva. Programa de incentivo à leitura Arca das Letras: estudo de caso da Comunidade Café sem Troco - DF. 2011. 83f. Monografia (Graduação em Biblioteconomia) - Universidade Federal do Maranhão, 2011.

FERRETTI, Mundicarmo. Encantaria de "Barba Soeira": Codó capital da magia negra? São Paulo: Siciliano, 2001.

FREIRE, Paulo. Ação cultural para a liberdade: e outros escritos. 8 ed. Rio de Janeiro: Paz e Terra, 1982 (O mundo hoje ; 10).

FREIRE, Paulo. A importância do ato de ler: em três artigos que se completam. 23 ed. São Paulo: Cortez, 1989. (Coleção Polêmicas do nosso século; $4)$.

FREITAS, Ilzeni Dias de. A práxis do professor rural. Dissertação (Mestrado) - Universidade Federal do Ceará, 1990.

GIL, Antonio Carlos. Como elaborar projetos de pesquisa. 4 ed. São Paulo: Atlas, 2004.
MARX, Karl. O capital. Crítica da economia política. Rio de Janeiro: Civilização Brazileira, 1968.

MINAYO, Maria Cecília de Souza; DESLANDES, Suely Ferreira; GOMES, Romeu. Pesquisa social: teoria, método e criatividade. 29 ed. Petrópolis: Vozes, 2010.

\section{MINISTÉRIO DO DESENVOLVIMENTO} AGRÁRIO. Relatório de execução: plano de execução 2010 - Territórios da Cidadania. Brasília, DF: MDA, 2011. Disponível em: $<\quad$ www.territoriosdacidadania.gov.br/ dotlrn/clubs / territriosrurais / xowiki / portlets/territorios/execucao/relatorio_ execucao?period $=20102 \&$ ponto_de controle=2010-12-31>. Acesso em: 28 abr. 2011.

MINISTÉRIO DO DESENVOLVIMENTO AGRÁRIO. Painel de indicadores: painel de indicadores gerenciais da Secretaria de Reordenamento Agrário. Brasília, DF: MDA, 2018.

MOURA, Flávia de Almeida. Escravos da precisão: economia familiar e estratégias de sobrevivência de trabalhadores rurais em Codó (MA). São Luís: EDUFMA, 2009.

NETTO, José Paulo. Introdução ao estudo do método de Marx. São Paulo: Expressão Popular, 2011.

RODRIGUES, Michelle de Brito. Análise do programa Arca das Letras em comunidades rurais em Santa Catarina. 2010. 92f. Monografia (Graduação em Biblioteconomia) - Universidade Federal de Santa Catarina, 2010.

SOARES, Cleide Cristina; CARNEIRO, Maria Elisabeth Ribeiro. Bibliotecas rurais para inclusão social no Brasil. Informação e sociedade, Brasília, DF, v.3, n.2, p.15-25, jan./jun., 2010. 
SOARES, Cleide Cristina. Implantação de TRIVINOS, Augusto Nibaldo Silva. Introdução Bibliotecas Rurais: manual para agentes de à pesquisa em ciências sociais: a pesquisa leitura e multiplicadores do programa Arca das qualitativa em educação. 20 reimp. São Paulo: Letras. Brasília, DF: MDA, 2011. Atlas, 2011.

SOUSA, João de Deus Lima. Codó: uma cidade para todos. Codó: Prefeitura Municipal de Codó, 2006. 